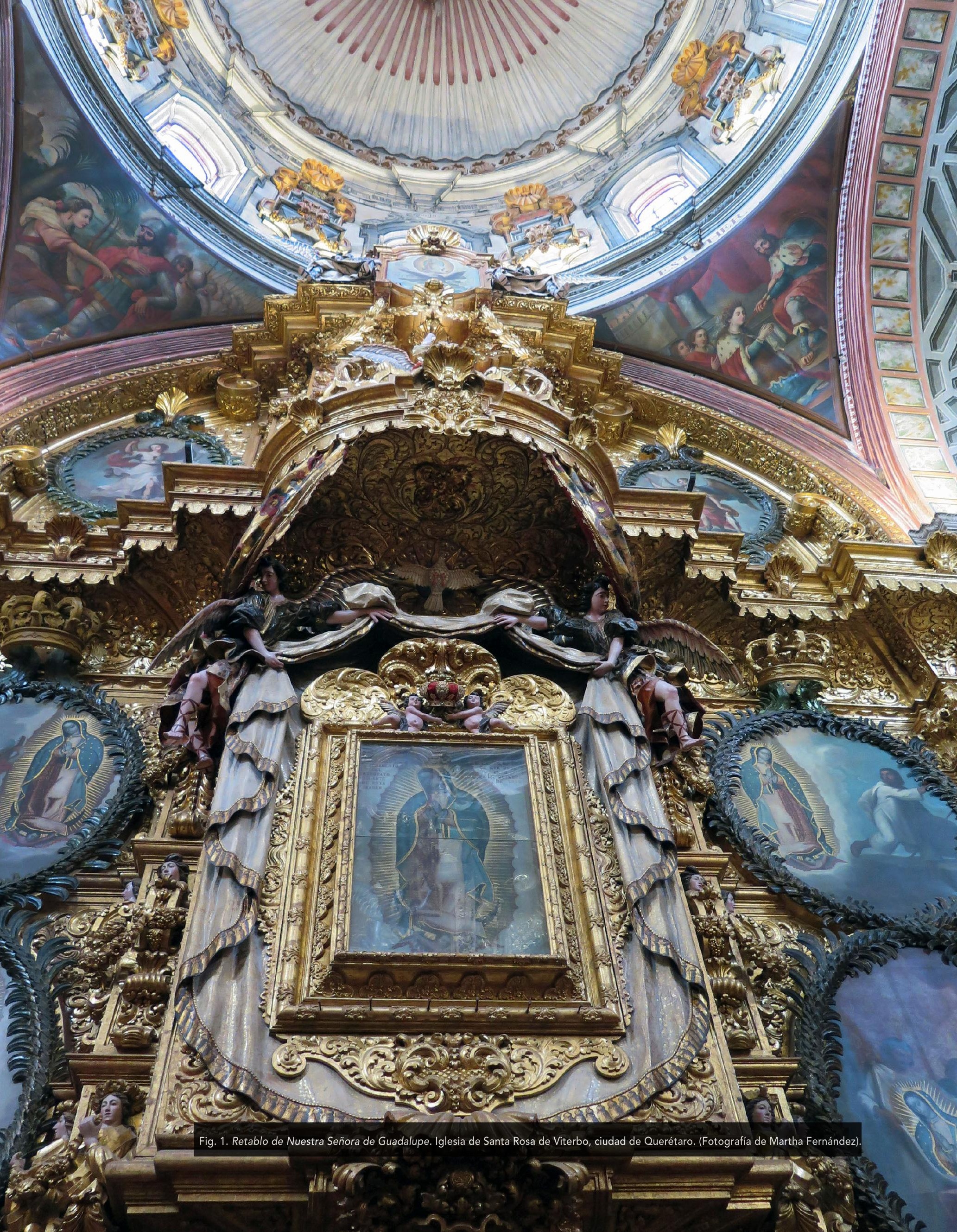




\title{
Arcos-cortinaje en la arquitectura barroca novohispana
}

Arched Drapery in New Spanish Baroque Architecture

\author{
Martha Fernández \\ Universidad Nacional Autónoma de México, México \\ marafermx@yahoo.com \\ https://orcid.org/0000-0002-1822-2299
}

\section{Resumen}

Los arcos que podemos mirar en la arquitectura barroca de la Nueva España muchas veces tienen formas tan variadas y ricas que dejan en un observador cuidadoso la impresión de estar mirando cortinas talladas en piedra. Este ensayo es precisamente una invitación a reflexionar acerca de la posibilidad de que la intención de los autores, patronos y propietarios haya sido esa, es decir, representar cortinajes. Las cortinas, los mantos y los doseles tuvieron una gran importancia desde el punto de vista simbólico, pues son representaciones del cielo y, desde el punto de vista formal, cumplen con los principios de movimiento, lujo, riqueza, dramatismo y teatralidad del arte barroco.

Palabras clave: arquitectura; arcos; cortinaje; dosel; simbolismo; Nueva España.

\begin{abstract}
The arches we see in the Baroque architecture of New Spain have such varied and rich forms that, to the careful observer, they give the impression of looking at drapes carved in stone. This article is an invitation to consider the possibility that those who commissioned or made them intended to imitate curtains. Curtains, cloaks, and canopies had an important symbolic function as representations of the sky and, from a formal perspective, manifested the movement, luxury, wealth, drama, and theatricality of Baroque art.
\end{abstract}

Keywords: architecture; arches; drapery; canopy; symbolism; New Spain.

Cómo citar este trabajo / How to cite this paper:

Fernández, Martha. "Arcos-cortinaje en la arquitectura barroca novohispana." Atrio. Revista de Historia del Arte, no. 25 (2019): 24-43.

(C) 2019 Martha Fernández. Este es un artículo de acceso abierto distribuido bajo los términos de la licencia Creative Commons Attribution-Non-

Commercial-ShareAlike 4.0. International License (CC BY-NC-SA 4.0). 
"La belleza y el placer estéticos no nacen de ningún otro sitio más que de la hermosura y la ornamentación”.

\section{La tela en la arquitectura novohispana}

Cuando Vitruvio explicó la manera de realizar las columnas jónicas escribió que en el momento en que los jonios construyeron un templo en honor de Diana, siguieron los mismos principios de proporción que habían regido la construcción de las columnas dóricas,

pero esta vez les dieron la delicadeza de un cuerpo de mujer. Primeramente, hicieron el diámetro de la columna igual a la octava parte de su altura, con el fin de darle un aire más esbelto; seguidamente imaginaron ponerle la basa hecha a manera de calzado; tallaron luego volutas a una y otra parte del capitel, queriendo imitar el cabello que cae en bucles a derecha e izquierda, y por medio de cimacios y festones, como cabellos arreglados sobre la frente, adornaron la parte anterior de los capiteles. Además, trazaron estrías a lo largo del fuste de la columna, a imitación de los pliegues de la túnica de las matronas. De este modo, con estos matices, vinieron a inventar esos dos géneros de columnas [dórica y jónica], imitando en las unas, la simplicidad desnuda y despreocupación del cuerpo masculino y en las otras la delicadeza, el ornato y las proporciones del de la mujer.

Es decir, que las estrías, son una representación abstracta de las telas de las túnicas que vestían las mujeres en la Antigüedad, talladas en piedra o madera, moldeadas en estuco o realizadas en cualquier otro material utilizado en la arquitectura para su ornamentación. Esta solución fue frecuente y no se utilizó solamente en columnas jónicas, sino en los soportes de todos los órdenes arquitectónicos.

Durante el desarrollo del barroco en la Nueva España, fue habitual la imitación de las telas integradas a la arquitectura y a la retablística. Precisamente en los retablos barrocos, fue recurrente la incorporación de mantos, pabellones y cortinas realizados con tela encolada para darles mayor realismo, como los encontramos, por ejemplo, en el mayor, dedicado a la Virgen de Guadalupe en la parroquia de Dolores Hidalgo, Guanajuato, ${ }^{2}$ que enmarca el cuadro de la titular; en el de Nuestra Seńora del Pilar en la parroquia de Santa Prisca de Taxco, Guerrero, ${ }^{3}$ que abraza el fanal donde se encuentra la escultura de la Virgen; y en el de Nuestra Señora de los Dolores de la iglesia de Santa Clara en la ciudad de Querétaro, ${ }^{4}$ cuya tela azul forma un complejo adorno en forma de abanicos. En el retablo dedicado a la Virgen de Guadalupe que se localiza en uno de los muros laterales de la iglesia queretana de Santa Rosa de Viterbo, ${ }^{5}$ se levantan una cortina y un dosel de tela encolada superpuestos; aquella, enmarca el cuadro de la titular y el dosel es un aparato circular que sobresale del retablo y del que cuelgan un pabellón con borlas y una cortina que se pliega hacia el paramento del retablo (Fig. 1).

1. Marco Vitruvio Polión, Los diez libros de arquitectura, lib. 4, cap. 1, trad. Agustín Blánquez, con prólogo y notas de Agustín Blánquez (Barcelona: Editorial Ibera, 1997), 87-88.

2. Gracias a su estilo artístico y la presencia de los estípites se sabe que este retablo es del siglo XVIII.

3. Este retablo fue realizado por el ensamblador Isidoro Vicente de Balbás, entre 1752 y 1758. Elisa Vargas Lugo, La iglesia de Santa Prisca de Taxco, 2. a ed. (México: Universidad Nacional Autónoma de México, Instituto de Investigaciones Estéticas, Coordinación de Humanidades, Coordinación de Difusión Cultural, Seminario de Cultura Mexicana, 1999), 77: Guillermo Tovar de Teresa, Repertorio de artistas en México, 3 t. (México: Grupo Financiero Bancomer, 1995-1997), 1:124.

4. Este retablo fue realizado por Francisco Martínez Gudiño y fue concluido el año de 1765. Mina Ramírez Montes, Niñas, doncellas, vírgenes eternas. Santa Clara de Querétaro (1607-1864) (México: Universidad Nacional Autónoma de México, Instituto de Investigaciones Estéticas, 2005), 227.

5. Este retablo es del siglo XVIII y se puede atribuir al ensamblador Pedro Rojas. Mina Ramírez Montes, "Retablos," en Querétaro ciudad barroca, coord. Juan Antonio Isla Estrada (Querétaro: Dirección de Patrimonio Cultural, Secretaría de Cultura y Bienestar Social, Gobierno del Estado de Querétaro, 1988 ), 169. 


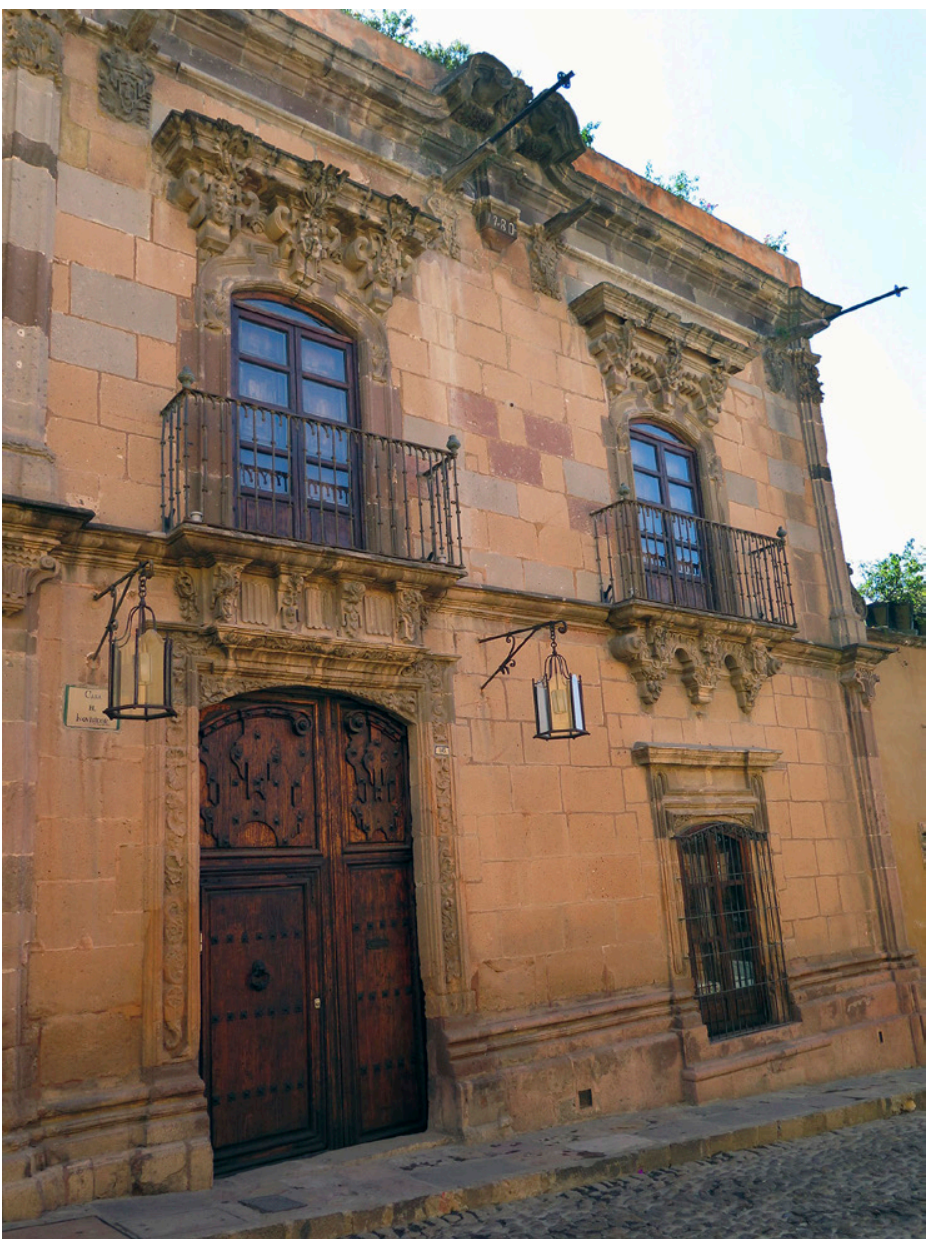

Fig. 2. Fachada de la Casa del Inquisidor. Ciudad de San Miguel de Allende, Guanajuato. (Fotografía de Martha Fernández). lletas que cuelgan del segundo piso del claustro del convento de San Agustín de Zacatecas, muy decoradas y terminadas en medallones circulares. ${ }^{11}$
Igualmente, en la arquitectura en piedra y en los retablos de madera, particularmente del siglo XVIII, fue usual la presencia de las guardamalletas que imitaban los tapices y pendones que se colgaban en las ventanas y en los balcones de los edificios públicos y de los palacios los días de fiestas y procesiones, aunque las guardamalletas se realizaron lo mismo para la arquitectura civil que para la religiosa. En las iglesias, fueron utilizadas especialmente en las portadas estípite, precisamente como adorno de los pedestales de esas pilastras; así las encontramos, por ejemplo, en las portadas del Sagrario Metropolitano de la Ciudad de México, ${ }^{6}$ en la portada principal de templo de San Francisco Javier en Tepotzotlán, Estado de México ${ }^{7}$ y en la iglesia de la Compañía de Jesús en la ciudad de Guanajuato. ${ }^{8}$ Pero también las podemos observar bajo columnas salomónicas, como en la espléndida portada principal de la catedral de Nuestra Señora de los Zacatecas y también como colgantes de los capiteles de pilastras, como se observan en la portada lateral de la iglesia de Santo Domingo en la Ciudad de México. ${ }^{10}$ Son dignas de mencionarse, las guardama-

$$
\text { terminadas en medallones circulares. }
$$

6. Construido por el arquitecto Lorenzo Rodríguez de 1749 a 1768. Manuel Toussaint, La Catedral de México y el Sagrario Metropolitano: su historia, su tesoro, su arte, 2. ${ }^{a}$ ed. (México: Editorial Porrúa, 1973), 247-48; Jorge Alberto Manrique, "Sagrario Metropolitano de la Catedral de México," en La Catedral de México, 2." ed., coords. Xavier Cortés Rocha, Martha Fernández, y Armando Ruiz Castellanos (México: Consejo Nacional para la Cultura y las Artes, 2015), 313-14.

7. Construido por el arquitecto Ildefonso de Iniesta Bejarano hacia 1754-1758. Tovar de Teresa, Repertorio de artistas en México, 2:190.

8. Iglesia construida por el arquitecto Felipe de Ureña hacia el año de 1765, con el proyecto de fray José de la Cruz. Fátima Halcón, Felipe de Ureña. La difusión del estípite en Nueva España (Sevilla: Universidad de Sevilla, Secretariado de Publicaciones, 2012), 104, $106-7$.

9. La construcción de la catedral actual se inició el año de 1729 con el proyecto de Domingo Ximénez Hernández. La iglesia se terminó el año de 1752 y la portada principal fue concluida el año de 1745. Clara Bargellini, La arquitectura de la plata. Iglesias monumentales del centro-norte de México. $1640-1750$ (México: Universidad Nacional Autónoma de México, Instituto de Investigaciones Estéticas, Turner, 1991), 273-78; Federico Sescosse Lejeune, "Catedral de Zacatecas. Nuestra Señora de los Zacatecas," en Catedrales de México, ed. Carmen Valles Septién (México: CVS Publicaciones, 1993), 188.

10. La iglesia actual fue comenzada a construir entre 1716 y 1720 y fue bendecida el año de 1736 . Su autoría se atribuye a los arquitectos Pedro de Arrieta y Miguel Custodio Durán. Gacetas de México. Castorena y Ursúa (1722) - Sahagún y Arévalo (1728-1742), con introducción de Francisco González de Cosío (México: Secretaría de Educación Pública, 1950), 2:15, 8:354. La atribución de la autoría la han planteado muchos autores; en lo personal considero más factible que sea del arquitecto Pedro de Arrieta, entre otras cosas que tienen que ver con su estilo arquitectónico, porque como bien afirma Guillermo Tovar de Teresa, existe un contrato a favor de ese arquitecto para la construcción de la iglesia del año de 1716 y por la que recibió 3,600 pesos de oro. Tovar de Teresa, Repertorio de artistas en México, 1:108.

11. El claustro, que actualmente se utiliza como oficinas del obispado, fue reconstruido en la segunda mitad del siglo XVIII. Eugenio Noriega Robles, Zacatecas. Crónica de una ciudad minera (México: San Ángel Ediciones, 1992), 74. 
En la arquitectura civil las guardamalletas también fueron muy utilizadas, pues era como dejar los tapices que colgaban en las fiestas de manera permanente, de forma tal que podemos verlos bajo el vano de ventanas y balcones en varios edificios de la Ciudad de México, como el palacio de Iturbide ${ }^{12}$ y el de los Mascarones. ${ }^{13}$ Igualmente, se pueden mencionar, por su riqueza, la enorme guardamalleta que se encuentra en una de las ventanas de la llamada Casa del Inquisidor ${ }^{14}$ (Fig. 2) y las que adornan los vanos del segundo piso de la casa de los condes de Jaral de Berrio, ${ }^{15}$ ambos edificios en la ciudad de San Miguel de Allende, Guanajuato.

Asimismo podemos encontrar guardamalletas desplegadas como pendones en los fustes de las pilastras, como las del patio principal del hospital de Belén de la Ciudad de México, ${ }^{16}$ las que sostienen el portal de la Casa Escala, de la ciudad de Querétaro ${ }^{17}$ y los contrafuertes, tallados a manera de pilastras, del patio principal de la Casa Canal de San Miguel de Allende. ${ }^{18}$

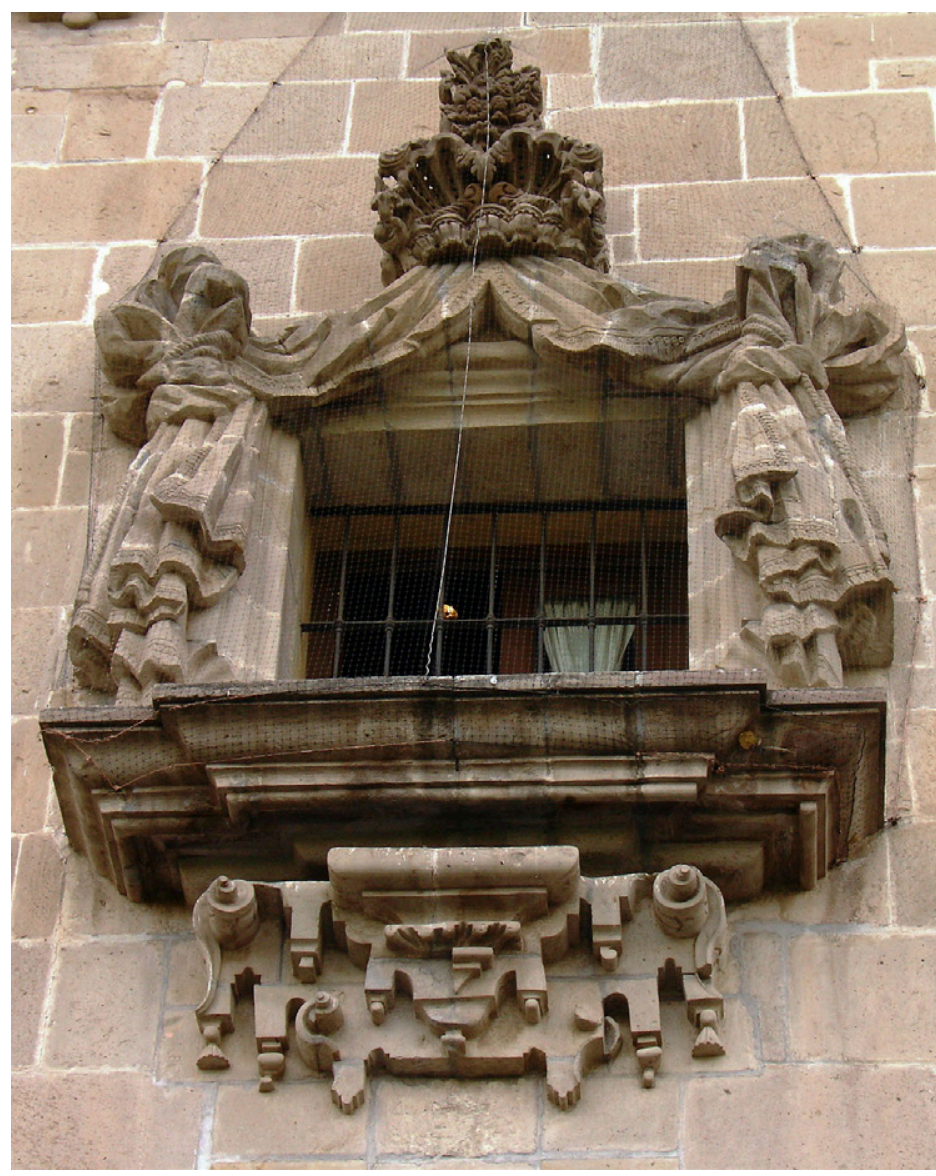

Fig. 3. Ventana de la fachada de la Casa Escala. Ciudad de Querétaro. (Fotografía de Martha Fernández).

En el palacio de Iturbide, una enorme guardamalleta decorada se despliega del arquitrabe para caer en el vano de ingreso y en la Casa Canal prefirieron abrirlas directamente sobre la puerta de madera de la entrada.

Los canteros de la Nueva España dominaron a tal grado su oficio que también tallaron cortinas y doseles, como aquella que luce una de las ventanas de la Casa Escala de Querétaro, con sus dos hojas abiertas

12. Hoy es sede de Fomento Cultural Banamex. Fue construido por el arquitecto Francisco Antonio Guerrero y Torres de 1779 a 1785. Martha Fernández, "El palacio de Iturbide," en Casas señoriales del Banco Nacional de México (México: Fomento Cultural Banamex, 1999), 179.

13. Hoy se encuentra en ese edificio un Laboratorio de Idiomas de la Universidad Nacional Autónoma de México. Se desconoce el nombre de su autor, pero se sabe que la fachada fue construida de 1766 a 1771 y su interior es del siglo XIX. Pedro Rojas, La casa de los Mascarones (México: Universidad Nacional Autónoma de México, Instituto de Investigaciones Estéticas, Imprenta Universitaria, 1985), 13.

14. Se le conoce como "la Casa del Inquisidor," aunque en realidad perteneció a la familia Castilblanque. Su construcción se terminó el año de 1780. Francisco de la Maza, San Miguel de Allende. Su historia. Sus monumentos (México: Frente de Afirmación Hispanista, 1972 ), 86.

15. En su puerta tiene una inscripción que reza: "Año del Señor 1791." Aunque Francisco de la Maza leyó "1797" no creo que sea correcto. De todos modos, supongo, como dicho autor, que la inscripción de la puerta marca el año en que se concluyó su construcción. Maza, 86.

16. La construcción del hospital se inició el año de 1758 y en una de las ventanas del claustro principal tiene la fecha de 1766 en que posiblemente se concluyó. Su autor fue el arquitecto Lorenzo Rodríguez. José María Marroqui, La ciudad de México, 3 t., 2. ed. facsimilar (México: Jesús Medina Editor, 1969), 1:574; Josefina Muriel, Hospitales de la Nueva España, 2 t., 2. ${ }^{a}$ ed. (México: Universidad Nacional Autónoma de México, Instituto de Investigaciones Históricas, Cruz Roja Mexicana, 1991), 2:95; Guillermo Tovar de Teresa, Bibliografía novohispana de arte, 2 t., (México: Fondo de Cultura Económica, 1988), 2:38.

17. Casa del regidor Tomás López de Escala, siglo XVIII. Mina Ramírez Montes, "Arquitectura civil," en Querétaro ciudad barroca, coord. Juan Antonio Isla Estrada (Querétaro: Dirección de Patrimonio Cultural, Secretaría de Cultura y Bienestar Social, Gobierno del Estado de Querétaro, 1988 ), 94.

18. Construida a finales del siglo XVIII. Maza, San Miguel de Allende, 79. 


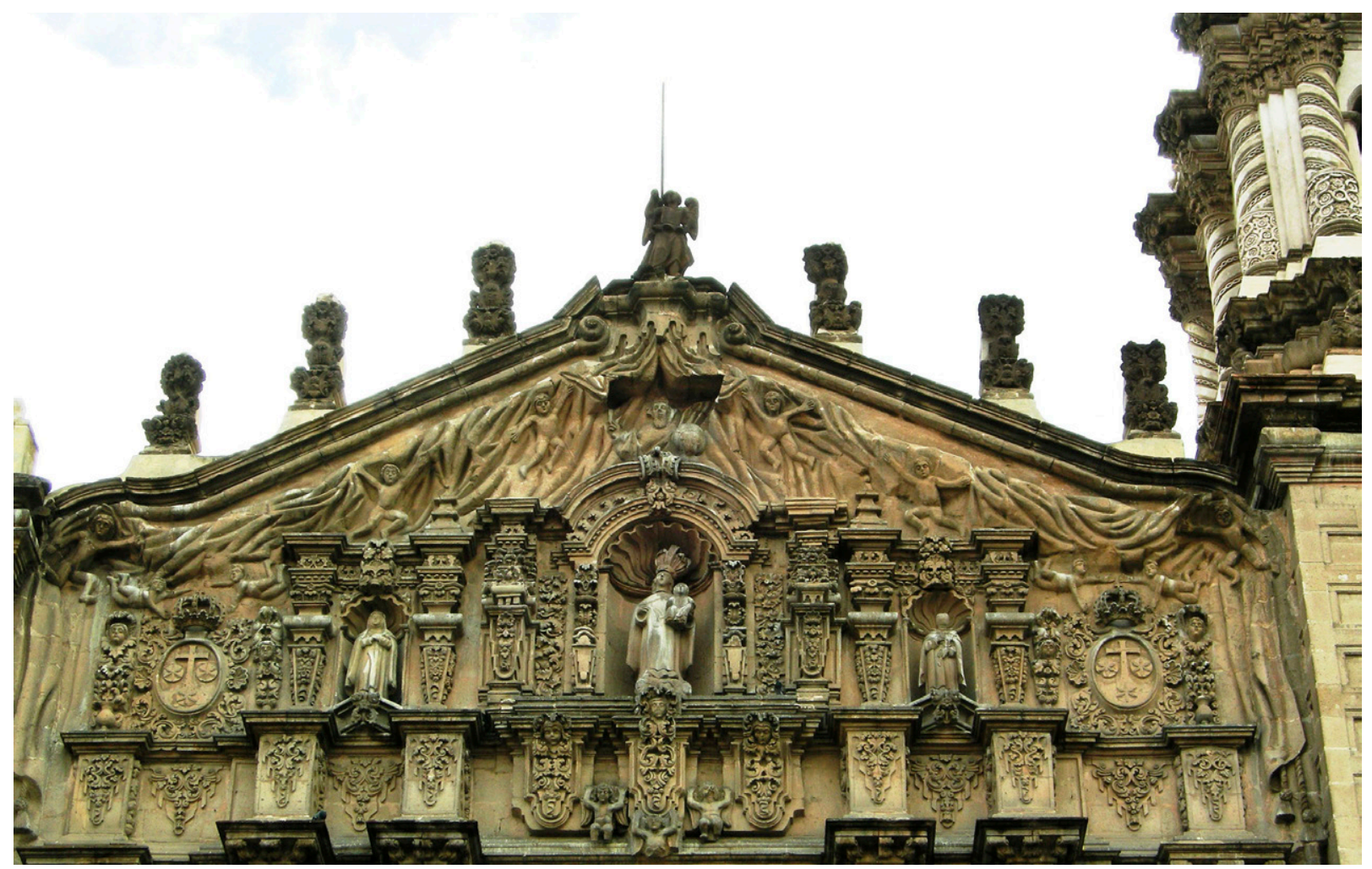

Fig. 4. Frontón del remate de la iglesia del Carmen. Ciudad de San Luis Potosí. (Fotografía de Martha Fernández).

que caen de un complejo corchete compuesto por borlas, conchas y acantos, el cual sirve de soporte a un ramo de flores que sobresale pegado al muro; al estar abierta, pero retenida al centro en la parte superior, se forma un arco conopial. Cada hoja de esa cortina está sujeta con un cordón que culmina en una borla; la tela que queda suelta deja ver varios pliegues y un completo bordado en la bastilla. (Fig. 3) El dosel que cubre la custodia en la estampa de la iglesia de la Santísima Trinidad de la Ciudad de México, ${ }^{19}$ es pequeño, pero está bien detallado; está conformado por un paño anudado al centro con un cordón que forma un anillo de donde sobresale una imitación de la tela trenzada, formando una especie de llama; el cordón cae a los lados y culmina con borlas, mientras que la "tela" cubre una apaisada media naranja y se despliega para cobijar la custodia del Santísimo, flanqueada por dos ángeles. Asimismo, es digno de mencionarse el extraordinario manto tallado en piedra que se encuentra en el frontón que remata la portada principal de la iglesia del Carmen, en la ciudad de San Luis Potosí; ${ }^{20}$ en este caso, no es más que un paño, que se extiende desde un arco conopial tallado al centro, debajo del cual se encuentra la figura de Dios padre, en actitud de bendecir, sosteniendo el mundo con su mano izquierda; a los lados, varios angelitos hacen el esfuerzo por mantener el manto abierto, lo que produce en él los muchos pliegues que podemos observar; este frontón es una representación clara de las citas bíblicas que hacen referencia a la tienda o carpa como imagen del cielo; de acuerdo con Isaías (40:22), "Él tiende los cielos como un toldo / y los despliega como una tienda de morada." ${ }^{21}$ (Fig. 4)

\footnotetext{
19. Iglesia construida por el arquitecto Ildefonso de Iniesta Bejarano de 1755 a 1781. Tovar de Teresa, Repertorio de artistas en México, 2:190.

20. Iglesia construida por el arquitecto indígena José Lorenzo a partir de 1749. Fue dedicada el año de 1764. Alfonso Martínez Rosales, El gran teatro de un pequeño mundo. El Carmen de San Luis Potosí, 1732-1859 (México: El Colegio de México, Universidad Autónoma de San Luis Potosí, 1985), $179-96$.

21. Las citas bíblicas fueron tomadas de la Sagrada Biblia, versión directa de las lenguas originales por Eloíno Nácar Fuster y Alberto Colunga, O. P. (Madrid:
} 


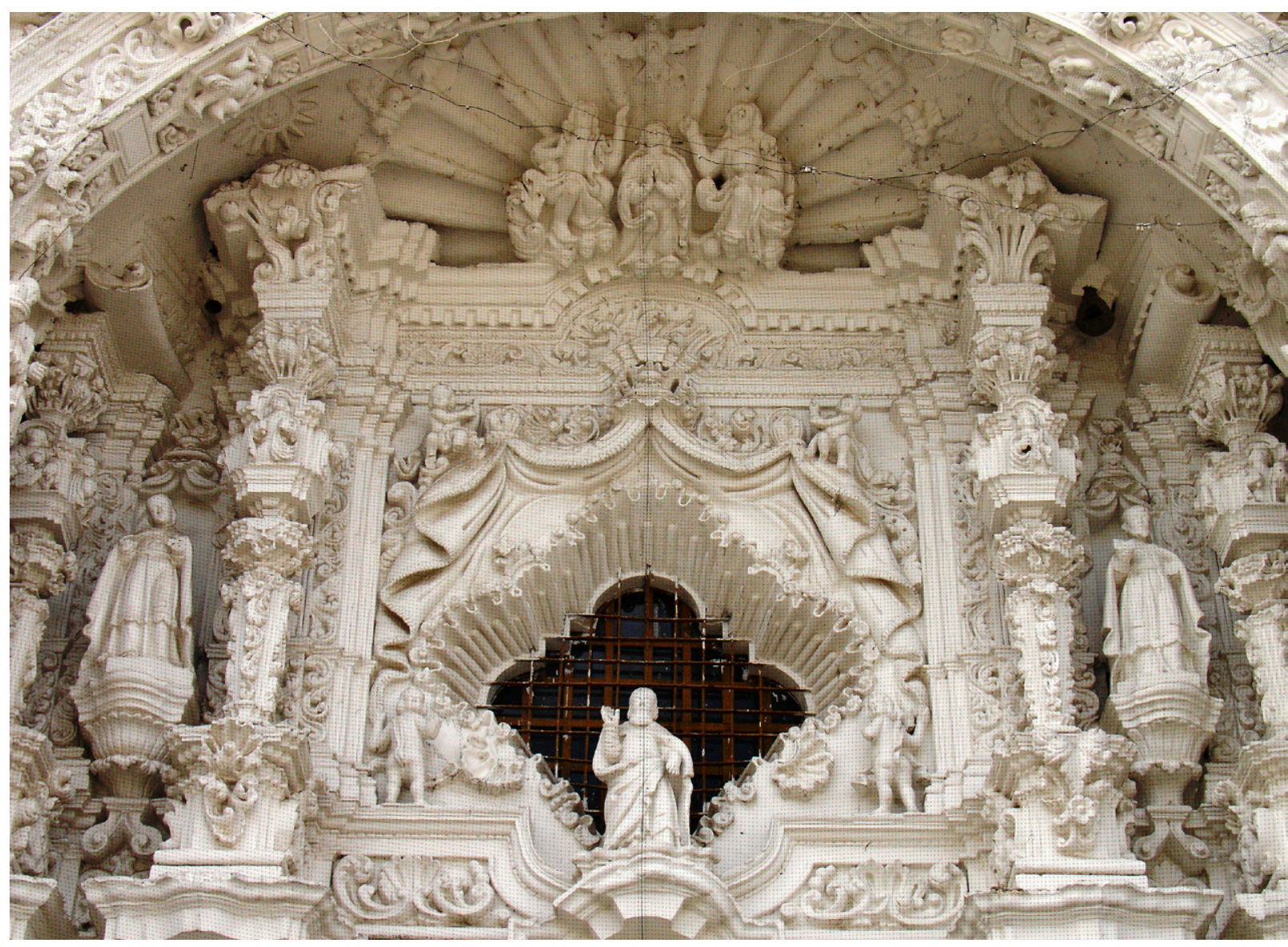

Fig. 5. Iglesia de San Nicolás de Bari. Panotla, Tlaxcala. (Fotografía de Martha Fernández).

El yeso fue un material magnífico para esos fines, de manera que, en iglesias como el santuario de Nuestra Señora de Ocotlán, ${ }^{22}$ se despliega un manto para dar abrigo a la imagen de la Virgen; se abre en dos hojas, cada una de las cuales está sujeta, como en el caso de la cortina de la Casa Escala, por medio de un cordón; el pańo de estuco tiene varios pliegues y de toda su orilla cuelgan borlas, algunas de las cuales, por desgracia han desaparecido. Lo mismo ocurre en la iglesia de Panotla, en la que el manto cobija la figura de San Nicolás de Bari, su titular, pero a diferencia del anterior, en el centro se forma un arco conopial, el paño está sostenido por angelitos y es más sencillo, pero no por ello menos plegado. ${ }^{23}$ (Fig. 5)

Claro que todos estos ejemplos nos muestras obras que podríamos calificar como figurativas y, por ello, muy evidentes para quien las contempla, pero se ha reparado poco en las formas abstractas, aunque igualmente significativas, de algunas soluciones arquitectónicas como los muy ricos arcos que se encuentran en muchas portadas y patios, lo mismo en iglesias y conventos, que en casas y palacios privados construidos a lo largo y ancho de la Nueva España. Los diccionarios de arquitectura se contentan con darles los nombres técnicos

Biblioteca de Autores Cristianos, 1964)

22. En el cubo de una de las torres tiene la fecha de 1769, fecha en que se supone se terminó la construcción del santuario. Se encuentra en el actual Estado de Tlaxcala.

23. Por su estilo arquitectónico y la presencia de los estípites, se sabe que la iglesia fue construida en el siglo XVIII. Se encuentra en el actual Estado de Tlaxcala. 


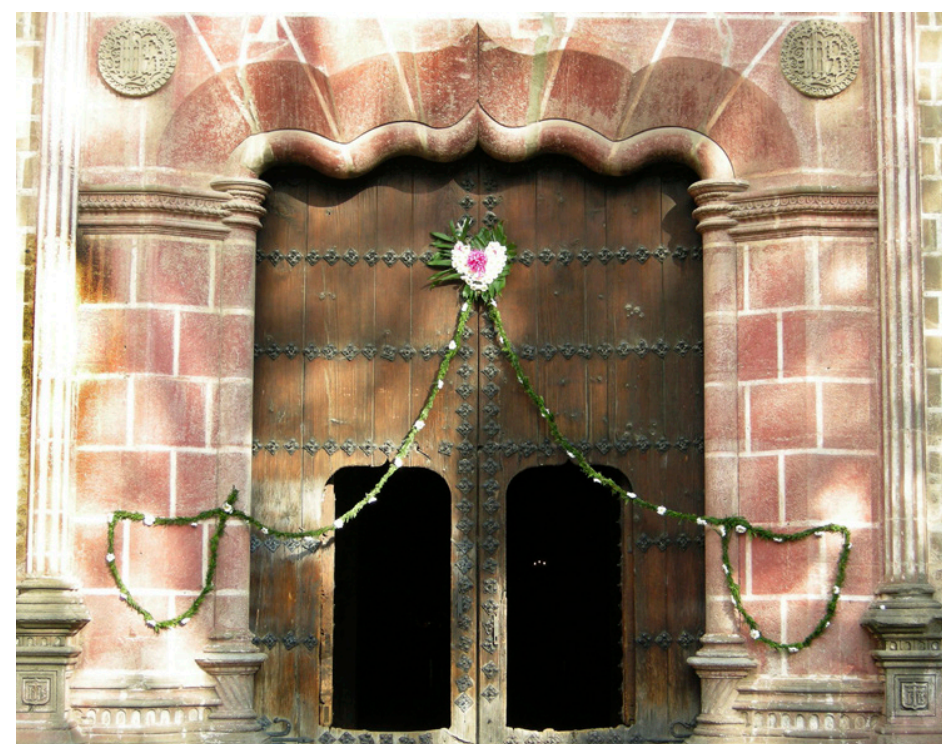

Fig. 6. Portada principal de la iglesia franciscana de San Miguel Huejotzingo. Puebla. (Fotografía de Martha Fernández). de medio punto, apuntados, bilobulados, trilobulados o poli lobulados; rebajados, carpaneles, curvilíneos, mixtilíneos, etcétera. Sin embargo, considero que por las variadas formas que adoptaron, también se podrían mirar de otra manera, pues si el espectador se detiene a observar sus soluciones formales y los elementos que las complementan como acodos, pinjantes, entrelazos, cordones, roleos, ménsulas y símbolos iconográficos, se puede formar una idea diferente a la de un simple arco mixtilíneo y caer en cuenta de que lo que en realidad parece que están representando son cortinas talladas en piedra, pero de manera abstracta, como las estrías que, como decía Vitruvio, representan las telas de las túnicas de las matronas sometidas.

\section{Arcos-cortinaje de la Nueva España}

Sin pretender llevar a cabo un catálogo de arcos novohispanos que, pienso, podrían considerarse cortinajes, citaré algunos ejemplos significativos que quizá ayuden en esta invitación a buscar en ellos otra intención que la meramente arquitectónica, a ver en ellos telones abiertos a los lujosos y complejos juegos ornamentales y simbólicos del barroco.

\section{Arquitectura religiosa}

Entre las soluciones formales más sencillas utilizadas para, creo, imitar una cortina se encuentran los arcos conopiales, que, junto con los apuntados, remontan su origen al arte medieval y fueron utilizados en la Nueva España desde el siglo XVI. En una cortina de tela común, el conopio se forma de manera natural y lógica, al separar dos hojas pero dejando unida la parte superior, donde se dibuja un triángulo que remata en una punta, es decir, que se constituye en un arco conopial de tela, exactamente como los arcos conopiales en cantería, madera, tela encolada y estuco de obras como las que cité antes, entre ellas, la cortina tallada en la ventana de la Casa Escala de Querétaro, el dosel de la portada del templo de Panotla, Tlaxcala o el manto tallado en piedra del frontón de la portada principal de la iglesia del Carmen, de la ciudad de San Luis Potosí.

Los arcos conopiales arquitectónicos, se comenzaron a utilizar en México en los conventos fundados por los frailes mendicantes donde fueron muy frecuentes, como se puede observar, por ejemplo, en la portada de la iglesia franciscana de San Miguel Arcángel, en Huejotzingo, Puebla, el cual es, además, lobulado (Fig. 6); igualmente, el arco de la portada que comunica el coro alto con el claustro, en el convento dominico 


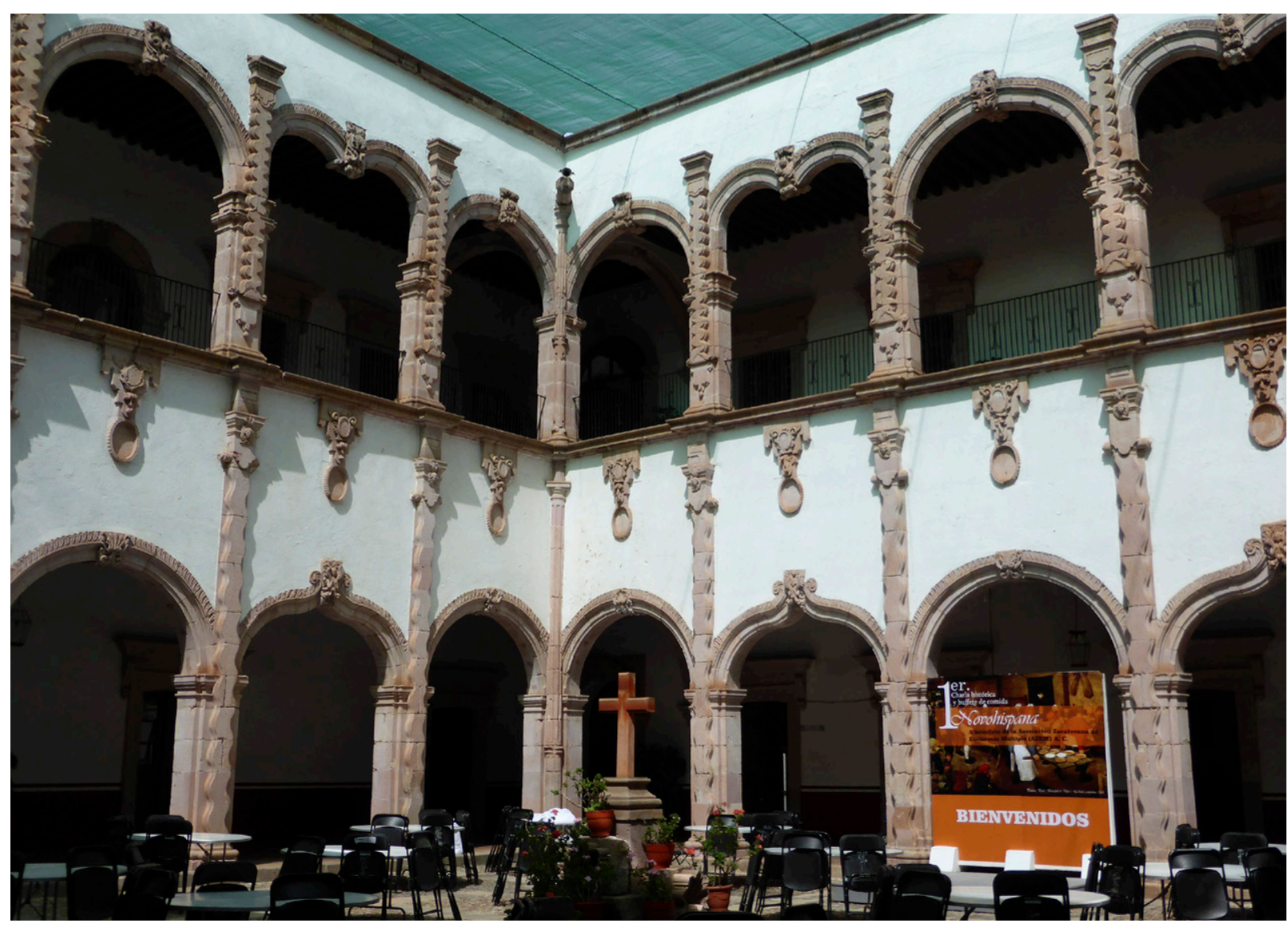

Fig. 7. Claustro del ex convento de San Agustín. Ciudad de Zacatecas. (Fotografía de Martha Fernández).

de San Juan Bautista en Coixtlahuaca, Oaxaca y los que se abren en la capilla abierta del convento de San Francisco, en la ciudad de Tlaxcala.

Pese a su antigüedad, estos arcos se emplearon también en el arte barroco novohispano con mucha frecuencia, como se aprecia, por ejemplo, en la portada principal de la iglesia de la Casa Profesa de la Compañía de Jesús, de la Ciudad de México, construida por el arquitecto Pedro de Arrieta de 1714 a 1720. Insisto en el nombre del autor porque Arrieta fue un arquitecto que podríamos calificar como de vanguardia en muchos sentidos, ${ }^{24}$ de manera que, al utilizar el arco conopial en una iglesia tan importante, más que un casual anacronismo, llevaba una intención que, en mi opinión, fue básicamente simbólica. Particularmente en el siglo XVIII, los arcos conopiales se combinaron con otros para hacer más complejo el conjunto, así los encontramos en el claustro del ex convento de San Agustín de la ciudad de Zacatecas. (Fig. 7) En sus dos niveles tiene arcos de medio punto; solo que en el primero, se alternan con arcos conopiales y, en el segundo, con arcos bilobulados. Es decir que, en el mismo claustro, tenemos tres tipos de arcos: medio punto, conopial y lobulado. Los arcos co-

24. Pedro de Arrieta fue autor, entre otras obras, del santuario de Guadalupe que todavía se conserva, el que construyó de 1695 a 1709 y del palacio de la Inquisición, hoy Museo de Medicina de la UNAM, que levantó de 1732 a 1736. Martha Fernández, "Pedro de Arrieta y la arquitectura del barroco mexicano," en E palacio de la Escuela de Medicina (México: Universidad Nacional Autónoma de México, Facultad de Medicina, Nacional Financiera, 1994), 52; María Concepción Amerlinck de Corsi, "Pedro de Arrieta y su tiempo," en Pedro de Arrieta. Arquitecto (1692-1738) (México: Universidad Nacional Autónoma de México, Facultad de Medicina, Consejo Nacional para la Cultura y las Artes, Dirección General de Sitios y Monumentos del Patrimonio Cultural, 2011$), 46$. 


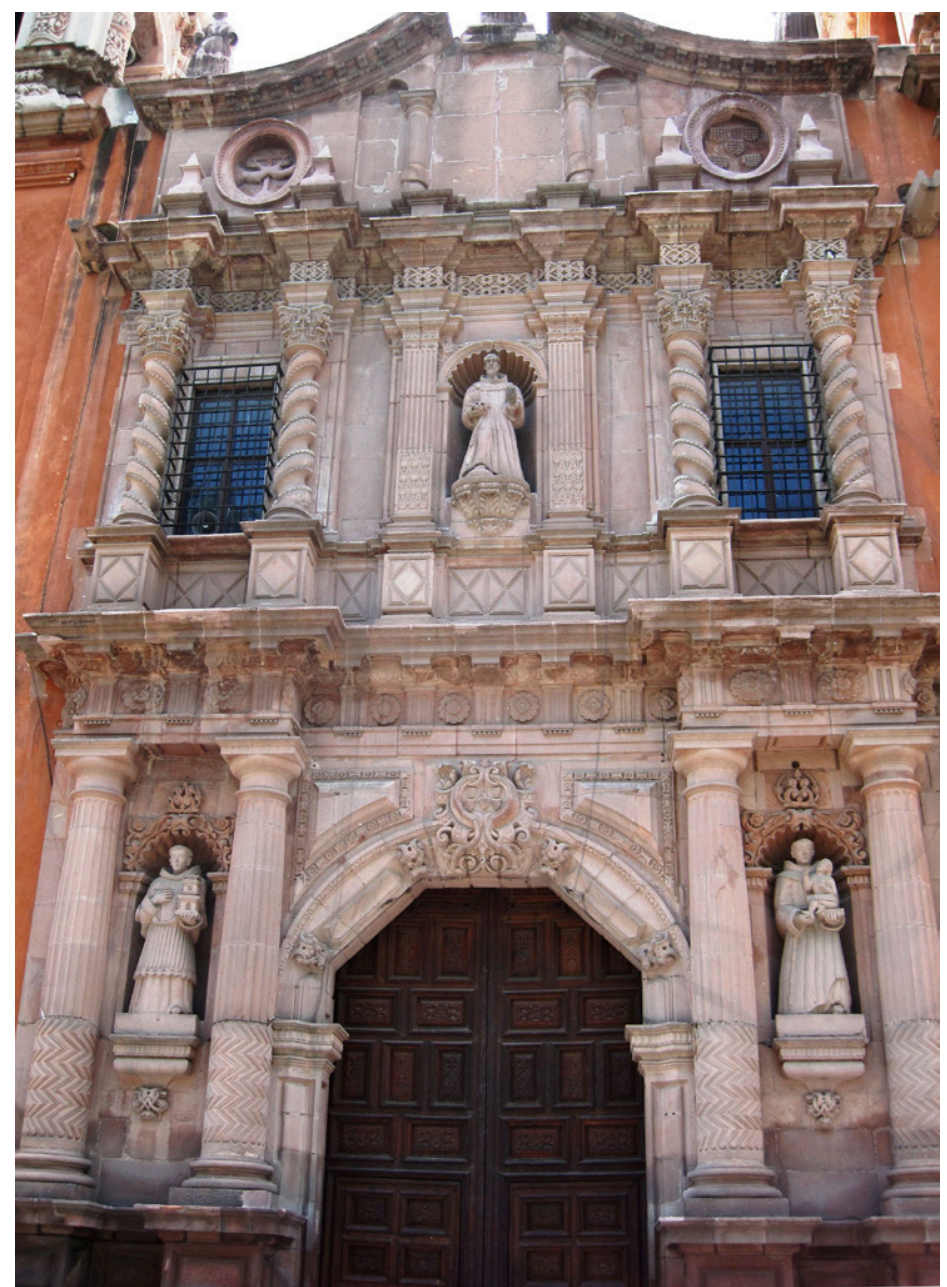

Fig. 8. Portada principal de la iglesia de San Francisco. Ciudad de San Luis Potosí. (Fotografía de Martha Fernández). nopiales semejan cortinas abiertas frente a nosotros y los bilobulados parecen galerías o pabellones. Sobre el extradós de todos ellos, se dejan ver orlas talladas en forma de volantes de tela, ceñidos por los broches que se prenden en sus piedras claves donde se alterna la presencia de niños con la de ángeles sosteniendo espigas.

También existen arcos que semejan cortinas a partir de dos superpuestos con diferente forma geométrica, como los de las portadas gemelas de la iglesia de Nuestra Señora de la Concepción de la Ciudad de México $^{25}$ y el que se abre en la portada principal de la iglesia de San Francisco de la ciudad de San Luis Potosí; ${ }^{26}$ el primero, de mediados del siglo XVII y el segundo, del siglo XVIII. Los de la iglesia concepcionista, están constituidos por un arco de medio punto en el que se inscribe otro semi hexagonal. En la piedra clave, se abren hojas de acanto ceñidas por lazos y roleos. El semi hexágono funciona a manera de cortina abierta, sujeta al medio punto con un prendedor realizado a base de hojas, lo que da motivo para que se afecte la forma de las jambas que adoptan un perfil circular.

Algo semejante ocurre con el doble arco que se abre en la iglesia de San Francisco de San Luis Potosí, (Fig. 8) solo que, en este caso, el inferior es semi octagonal. Para acentuar el aspecto de cortina, a los lados, se tallaron lazos a manera de hebillas y en la piedra clave, se labró un complejo broche compuesto por el escudo franciscano de las cinco llagas dentro de un medallón ovalado limitado por el cordón franciscano y rodeado todo de hojas y lazos. Sus impostas y sus jambas, en este caso, son mixtilíneas, para dar continuidad al perfil de los arcos superpuestos.

Igualmente, la portada principal de la capilla del Pocito del santuario de Nuestra Señora de Guadalupe, en la Ciudad de México, ${ }^{27}$ (Fig. 9) tiene un doble arco, pero en este caso, el exterior es mixtilíneo,

25. Convento fundado el año de 1540. La iglesia actual fue dedicada el año de 1655. Gregorio Martín de Guijo, Diario, 1648-1664, 2 t., (México: Editorial Porrúa, 1952), 2:36-37; Elisa Vargas Lugo, Las portadas religiosas de México, 2. ${ }^{a}$ ed. (México: Universidad Nacional Autónoma de México, Instituto de Investigaciones Estéticas, 1986), 71 .

26. La iglesia se comenzó a construir el año de 1686. Vargas Lugo, Las portadas religiosas de México, 217, pero la portada es del siglo XVIII, Joaquín Bérchez la sitúa hacia el año de 1710. Joaquín Bérchez, Arquitectura mexicana de los siglos XVII y XVIII (México: Grupo Azabache, 1992$), 193$.

27. Fue construida por el arquitecto Francisco Antonio Guerrero y Torres de 1777 a 1791. Ignacio González Polo, "Vida y obra del arquitecto Francisco Antonio Guerrero y Torres (1727-1792)" (tesis doctoral, Universidad Nacional Autónoma de México, 2006), 151-56. 
formando un pabellón que pareciera sostenerse en el muro por medio de una moldura que forma dos acodos en los extremos; en tanto que el arco interior es trilobulado del que cuelgan pinjantes que hacen las veces de borlas de una cortina.

Los arcos de las otras dos portadas de la misma capilla también parecen imitar cortinajes. El de la norte, es mixtilíneo y ascendente, formando ondas en el intradós y tableros en las enjutas, como si se tratara de tela plisada. De la piedra clave pende una guardamalleta ornada con un medallón al centro, cuyo relieve, por desgracia, está muy erosionado. Las pilastras que flanquean la portada son ondeantes y su perfil, en conjunto con el arco, parecieran semejar las telas en movimiento; están además recorridas por una decoración de hojas, a manera de trofeos, como si se tratara de lienzos decorados.

La portada sur, por su parte, tiene un arco poli lobulado, del que -como en la portada principal- cuelgan pinjantes, que lo adornan a manera de borlas. Sobre la piedra clave también se encuentra una

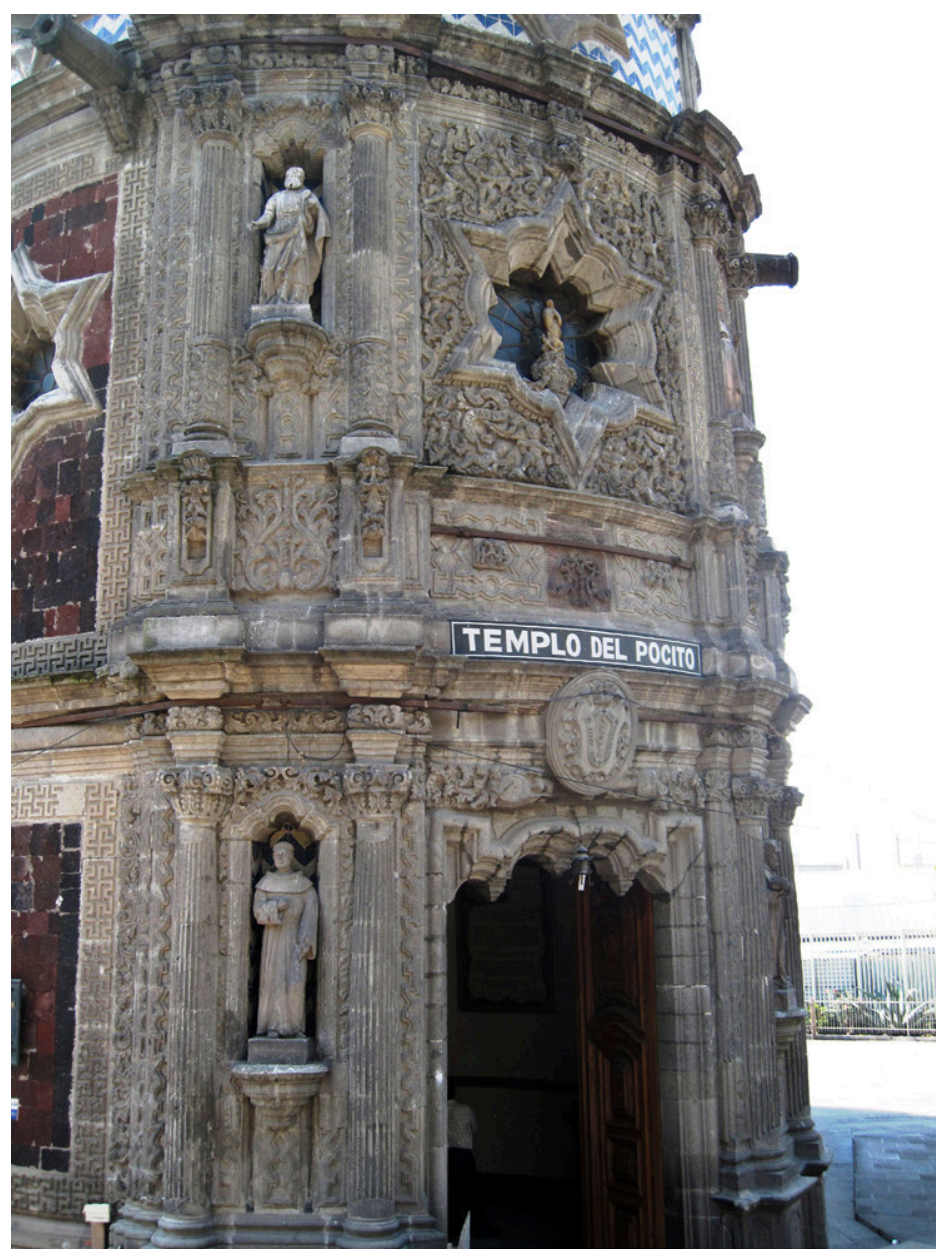

Fig. 9. Portada principal de la capilla del Pocito. Santuario de Nuestra Señora de Guadalupe, Ciudad de México. (Fotografía de Martha Fernández). guardamalleta, cuyo medallón se perdió. Las enjutas, igual que en la portada norte, tienen tableros y las pilastras que la limitan también son ondeantes, solo que, en este caso, están estriadas, imitando los pliegues de los paños al caer, tal como lo explicó Vitruvio. ${ }^{28}$

La portada de los Siete Príncipes de la iglesia del Carmen de San Luis Potosí, ${ }^{29}$ (Fig. 10) también tiene un arco de ingreso lobulado, en este caso de tres lóbulos: los más cercanos a las impostas son pequeños y casi circulares; en cambio, el central, es de gran tamańo y peraltado, pero todo el extradós se encuentra adornado con hojas de acanto, haciendo la función de hebillas, como si estos estuvieran sosteniendo una cortina al muro para mantenerla abierta. La solución que el arquitecto dio a los arcos de las portadas exte-

28. Las pilastras de las dos portadas laterales son salomónicas, como las proponía Guarino Guarini en su tratado: Guarino Guarini, Architettura civile, con introducción de Nino Carboneri y notas y apéndices de Bianca Tavessi La Greca (1737; reimpr., Milán: Edizioni il Polifilo, 1968), lámina 18. Sobre la incorporación que hace Guarini de la pilastra salomónica en la arquitectura, puede verse el artículo de Martha Fernández, "Los tratados del orden salomónico" y sobre la incorporación de la pilastra salomónica en la Nueva España, el artículo de Martha Fernández, "El soporte salomónico en la arquitectura novohispana," ambos recopilados en el libro de su autoría titulado: Estudios sobre el simbolismo en la arquitectura novohispana (México: Universidad Nacional Autónoma de México, Instituto de Investigaciones Estéticas, Instituto Nacional de Antropología e Historia, 2011), 49-58, 87-130.

29. Su nombre completo es "Portada de la Madre de Dios y de los Carmelitas y de los Siete Príncipes." Esta portada fue construida de 1758 a 1764 . Martínez Rosales, El gran teatro de un pequeño mundo, 284. 


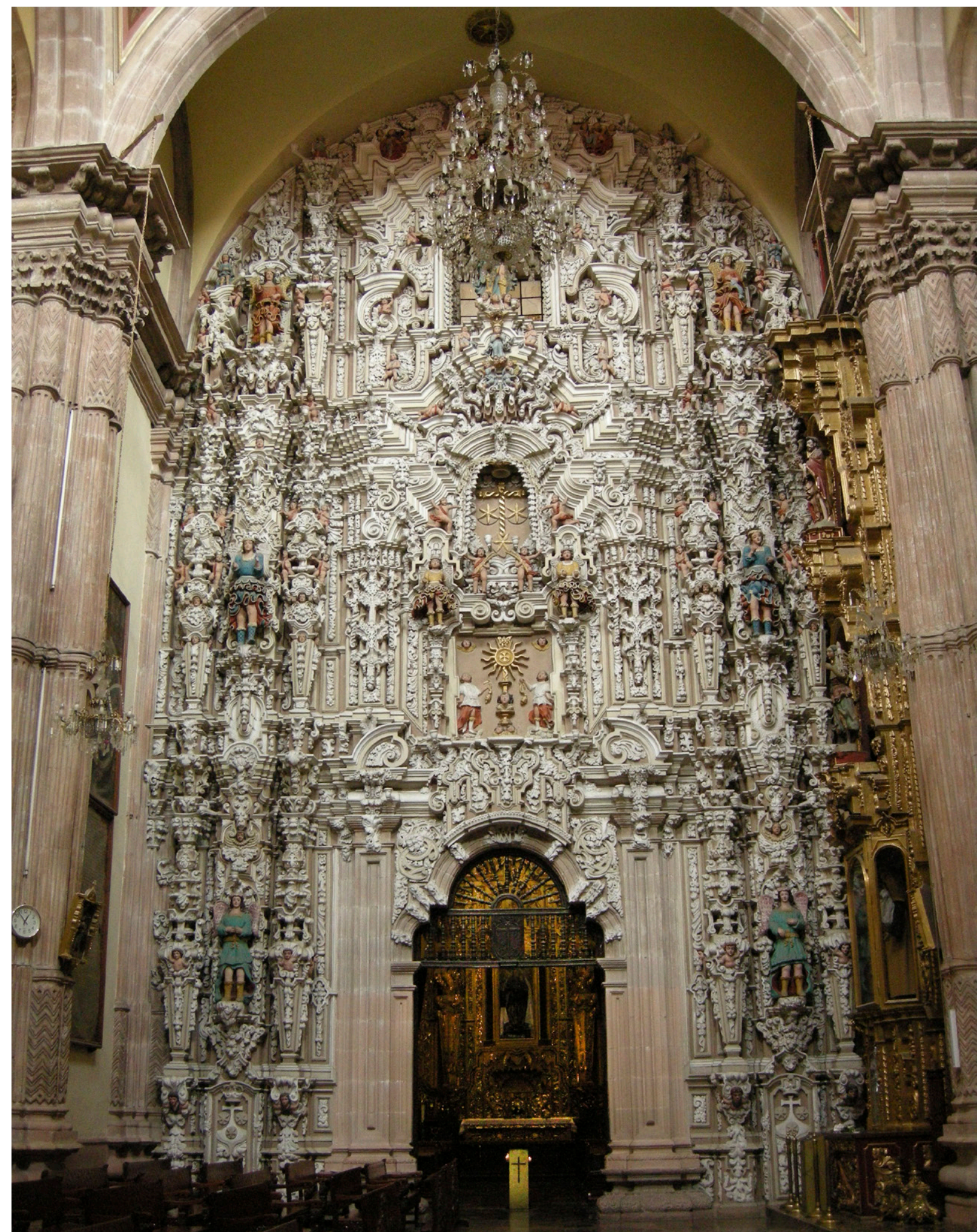

Fig. 10. Portada de los Príncipes. Iglesia del Carmen, ciudad de San Luis Potosí. (Fotografía de Martha Fernández). 
riores de la misma iglesia carmelita es muy interesante, pues tanto la principal como la Josefina, tienen arcos de medio punto, pero ambos están recorridos en todo el intradós por sendos pinjantes que le otorgan la impresión de ser poli lobulados y, nuevamente, los pinjantes funcionan a manera de borlas de una cortina.

La portada principal de la iglesia de San Diego de Guanajuato, ${ }^{30}$ también comparte la solución de los lóbulos; en este caso, con un doble arco: el interior de medio punto y el exterior poli lobulado, ornado por medio de pinjantes. Para completar la composición, las impostas tienen pequeños mascarones encima de una gruesa moldura con roleos, a manera de tela enrollada, bajo las cuales se alzan las hojas de acanto de los capiteles corintios, y cuelgan guardamalletas dobles de una sola punta.

En otros estudios dedicados a la imagen del cielo en la arquitectura religiosa de la Nueva España, ${ }^{31}$ se ha explicado

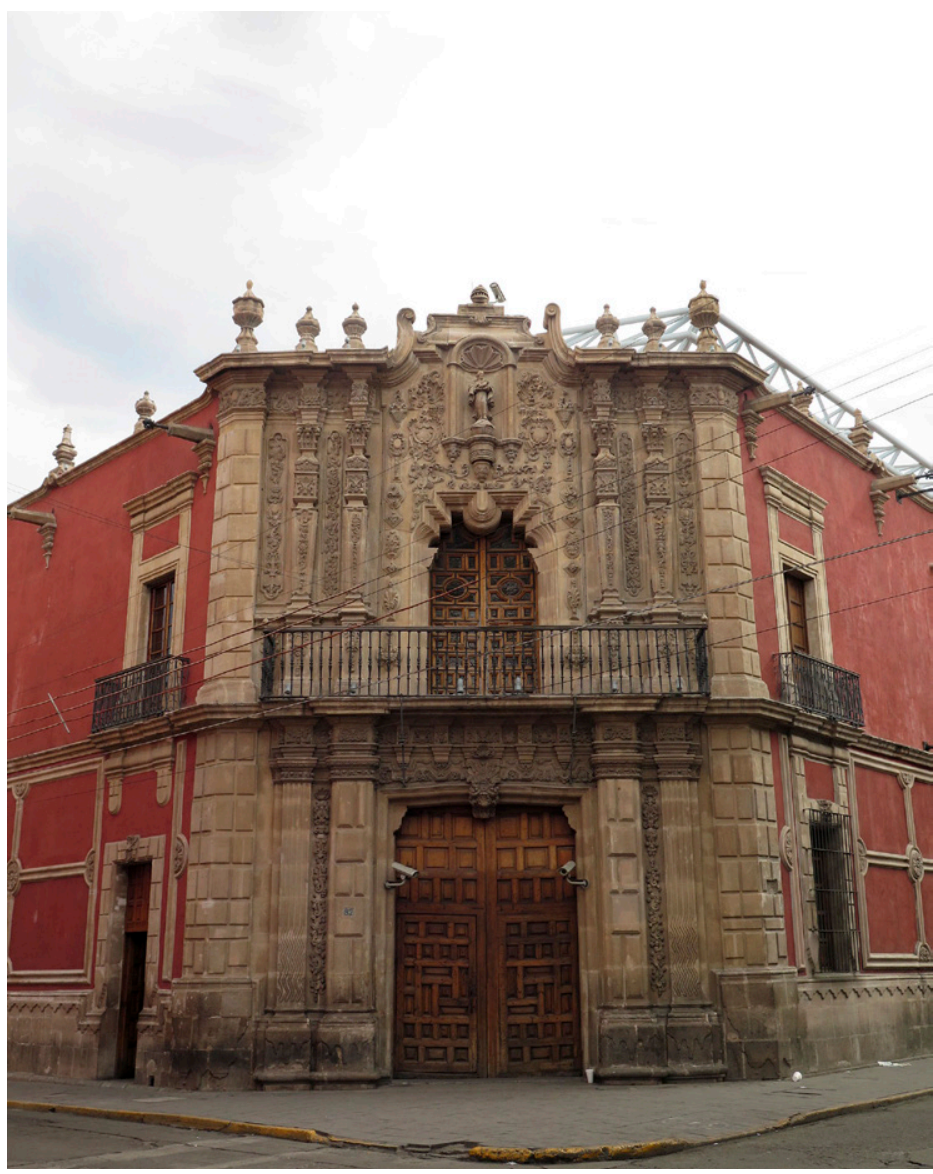

Fig. 11. Portada del palacio del conde del Valle de Súchil. Ciudad de Durango. (Fotografía de Martha Fernández). cómo los mantos, los doseles y los cortinajes se convirtieron en una forma de representarlo a partir de citas bíblicas como la de Isaías, que mencioné anteriormente y como la del Salmo 104:2 que a la letra dice: "Envuelto de luz como de un manto / despliegas los cielos como una tienda..." Igualmente, en esos mismos ensayos se comenta que, aunque esta idea no se desarrolló en el cristianismo, teóricos como Gérard de Champeaux y Dom Sébastien Sterckx, sostienen que, en cambio, se adoptó en la iconografía por influencia, claro, de la tradición judía, pero también de la romana, en la cual el Dios Coelus tenía la función de extender el manto curvo del cielo. ${ }^{32}$ De todo ello derivó que el cielo fuera concebido como una tienda que Dios extiende como cubierta de la Tierra.

Asimismo, en los artículos a los que me refiero, se ha advertido que tales elementos también recrean la tienda de Moisés en el desierto, es decir, la primera revelación del legendario y paradigmático Templo de Salomón. Como se plantea en los textos escriturarios, estando en el Monte Sinaí, Yahvé ordenó al profeta construir un tabernáculo donde sería adorado y donde se manifestaría, pero por estar en ese tiempo el pueblo

\footnotetext{
30. La portada data del año de 1784. Vargas Lugo, Las portadas religiosas de México, 115.

31. Martha Fernández, "La imagen del cielo en la arquitectura novohispana. Mantos, doseles y cortinajes," en Estudios sobre el simbolismo, 131-58; Martha Fernández, "La imagen de la tienda cósmica en los Santuarios del Tepeyac," Interpretatio. Revista de Hermenéutica 1, no. 2 (septiembre 2016-febrero 2017): 71-87.

32. Gérard de Champeaux y Dom Sébastien Sterckx, Introducción a los símbolos, trad. Abundio Rodríguez, O. S. B. (Madrid: Encuentro, 1992 ), 83.
} 
de Israel en tránsito hacia la tierra prometida, el templo que levantó fue propiamente una tienda desmontable y transportable, construida a base pieles y telas multicolores. ${ }^{33}$

Ambas tradiciones también formaron parte de la cultura de la Nueva España, lo que se puede comprobar en el sermón titulado La Maravilla Immarscesible y milagro continuado de María Santíssima Señora Nuestra, en su prodigiosa imagen de Guadalupe de México, que escribió el padre jesuita Juan de Goycoechea, el "día octavo del Novenario" que se llevó a cabo para la dedicación del santuario de Nuestra Señora de Guadalupe, "extramuros" de la Ciudad de México, el año de 1709. De acuerdo con el cronista, "el Soberano Artífice” hizo los cielos y “fabricó para su adoración un Templo,” el “Templo del mundo,” el cual, según él, mucho tenía de parecido con "este MARIANO Templo de GUADALUPE, fundado en el sitio inconstante de el Mexicano Lago, pero con la firmeza de aquel hermoso Cielo, que Trassumptó en el Ayate su dueño: y si copia el Templo a su Imagen, es este Templo una Imagen del Cielo." ${ }^{34}$ Goycoechea entonces comparó ese cielo con una capa; la capa con el santuario de Guadalupe y, por supuesto, esta con la tilma de Juan Diego. De acuerdo con su visión, así como sucede con el vestido, "la capa del cielo se ha de envejecer,"

y como quien muda de gala, y estrena vestido, has de estrenar, y mudar de Templo, y de Cielo, y el Cielo de tu Templo se ha de mudar en una Capa ... Pues Cielo Nuevo, que sea Capa, no hay otra, que la de Juan Diego, debajo de la Capa de el Cielo, porque con MARÍA, se trassundó todo el Cielo a aquella Capa ... Yo no dixera en el latino Idioma, con otra frase, lo que en el Mexicano Tylma, que cubre medio lado, como el Cielo, Capa de media Esphera. ${ }^{35}$

Si esto sucedía así en el pensamiento virreinal, podemos entender que en la estructura arquitectónica que tuvieron los templos y claustros novohispanos se hayan desarrollado elementos formales específicos para representar el cielo como tienda cósmica y como la tienda de Moisés en el desierto, como, por ejemplo, las bóvedas de nervaduras (a la manera gótica o formando diversas figuras geométricas), las bóvedas de pañuelo o las bóvedas de aristas, para simular las telas tensadas por estacas o las varillas con que se armaban las carpas. Los arcos-cortinaje forman parte de ese mismo conjunto de imágenes arquitectónicas, pues en una portada anuncian el ingreso al cielo que es la iglesia misma y en un claustro están representando el paraíso de los religiosos. En ese sentido, cabe recordar la frase inscrita en el friso del primer cuerpo de la portada principal de la iglesia conventual de San Juan Bautista de Coyoacán, en la Ciudad de México: "No está aquí algo distinto, sino la casa de Dios y la puerta del cielo. Ge. 28," ${ }^{36}$ pasaje que se refiere al sueño de Jacob y que precisa exactamente lo que son, representan y simbolizan los edificios sagrados. ${ }^{37}$

\section{Arquitectura civil}

En relación con la arquitectura civil, uno de los arcos más llamativos es el que se abre en el balcón del antiguo palacio de José del Campo Soberón, conde del Valle de Súchil, en la ciudad de Durango. ${ }^{38}$ (Fig. 11) Es

\footnotetext{
33. Éxodo $25: 10-22: 26: 1-37: 36: 8-38$.

34. Juan de Goycoechea, La maravilla immarcescible, y milagro continuado de María Santíssima Señora Nuestra, en su prodigiosa imagen de Guadalupe de México. Compite firmezas con su nuevo Templo, que la copia: adelanta duraciones al Cielo, que a su Efigie traslada; iguala permanencias con el Augusto Sacramento, de quien imita la Milagrosa Presencia en su Pintura. Reproducido en David A. Brading, Nueve Sermones Guadalupanos (1661-1758) (México: Centro de Estudios de Historia de México Condumex, 2005), 110-11.

35. Goycoechea, 113 .

36. Génesis 28:17.

37. Sobre este tema, se puede revisar el breve artículo de Martha Fernández, "Los templos como imagen de la casa de Dios y la puerta del cielo," en Inventario de arte religioso 2017 (México: Gobierno del Estado de Puebla, Secretaría de Cultura y Turismo, 2018), 150-51. Debajo de la inscripción transcrita y en el mismo friso existe otra que reza: "A 5 de abril. Año 1582."

38. Construido por el arquitecto Pedro Huertas y concluido el año de 1777. Hoy es una sucursal del banco Banamex. Clara Bargellini, "La casa del conde del Valle
} 
mixtilíneo y multi moldurado; su imposta es una zapata tallada en piedra. Del centro, como piedra clave, cuelga un pinjante a manera de enorme lágrima, que imita un pedazo de tela colgante, cuyos pliegues están representados por medio de molduras.

Aunque es en la ciudad de Querétaro donde se encuentra la mayor cantidad de arcos de variadas y caprichosas formas. En las casas habitación de Querétaro, construidas en el siglo XVIII, los patios fueron fundamentales, tanto así que existieron casas no con uno, sino con varios espacios de esa naturaleza; todavía, existe una, dedicada hoy a eventos especiales, conocida como "la Casa de los Cinco Patios." El clima favorable de la ciudad debió de hacer propicios esos lugares abiertos para la convivencia entre familiares y amigos de la sociedad queretana en la época virreinal. Así, los arcos de esos patios son en verdad ricos y muy diversos; de inmediato se percibe que su intención es adornar esos espacios como hacían con las habitaciones, dotarlos de la misma riqueza, singularidad

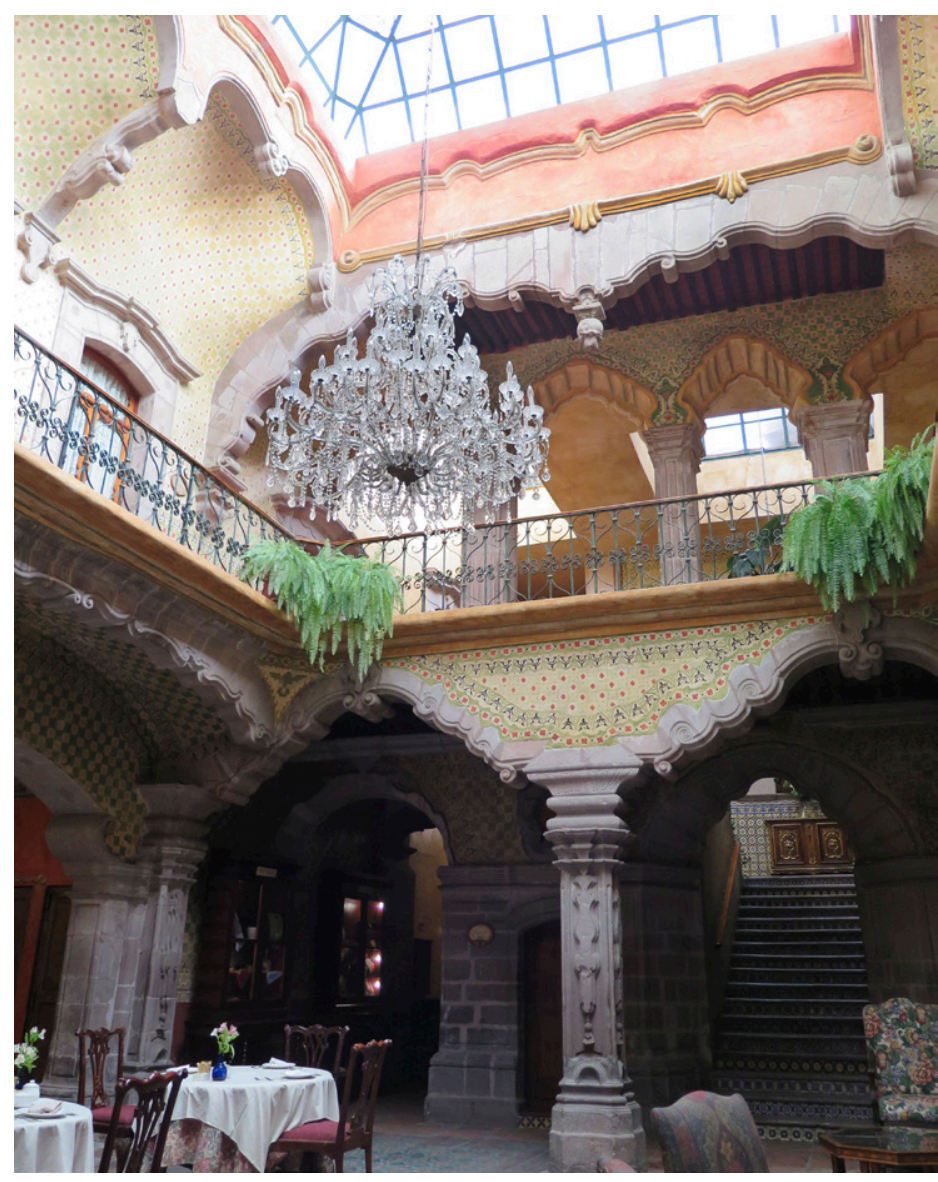

Fig. 12. Patio principal de la Casa de la Marquesa. Ciudad de Querétaro. (Fotografía de Martha Fernández) y cobijo que proporcionaban las cortinas que colgaban dentro, pero talladas en piedra. De esta manera, los arcos siempre son mixtilíneos y se forman a base de roleos, ménsulas en sucesión y molduras. Veamos, por ejemplo, los del patio principal de la Casa de la Marquesa del Villar del Águila. ${ }^{39}$ En el primer piso, se desplantan arcos curvilíneos, formando lóbulos deprimidos que ascienden hacia el centro; con roleos, se imitan las arrugas de la cortina y de la piedra clave cuelga un pinjante en forma de una flor abierta, que deja ver los pistilos. Las pilastras que sirven de apoyo a los arcos tienen, en sus fustes, complejas guardamalletas en forma de pilastras estípites, que culminan en su parte inferior con un cordón anudado, del que penden flecos; pareciera que las pilastras hubieran servido de base para apoyar las "telas" colgantes de las cortinas talladas en piedra que forman los arcos. En el segundo piso, sus dos costados principales tienen el mismo tipo de arcos que en la primera planta, mientras que, en los otros dos, los muros se convierten en bóvedas limitadas por arcos lobulados colocados transversalmente, que se apoyan en ménsulas mixtilíneas adornadas con roleos y rematadas por guardamalletas. Los arcos del arranque de la escalera son lobulados, mientras que los del desembarque son simplemente ondeados. Todo el conjunto semeja un muestrario de arcos mixtilíneos que, desde mi punto de vista, no son sino imitacio-

de Súchil," en Casas señoriales del Banco Nacional de México (México: Fomento Cultural Banamex, 1999), 134.

39. La casa perteneció al III marqués del Villar del Águila, José Antonio Fernández de Jáuregui y Urrutia y a su esposa Gertrudis Josefa de Villanueva Freire. Se le conoce como "Casa de la Marquesa." Fue concluida el año de 1756. Hoy es el Hotel de la Marquesa. Ramírez Montes, "Arquitectura civil," 84. 


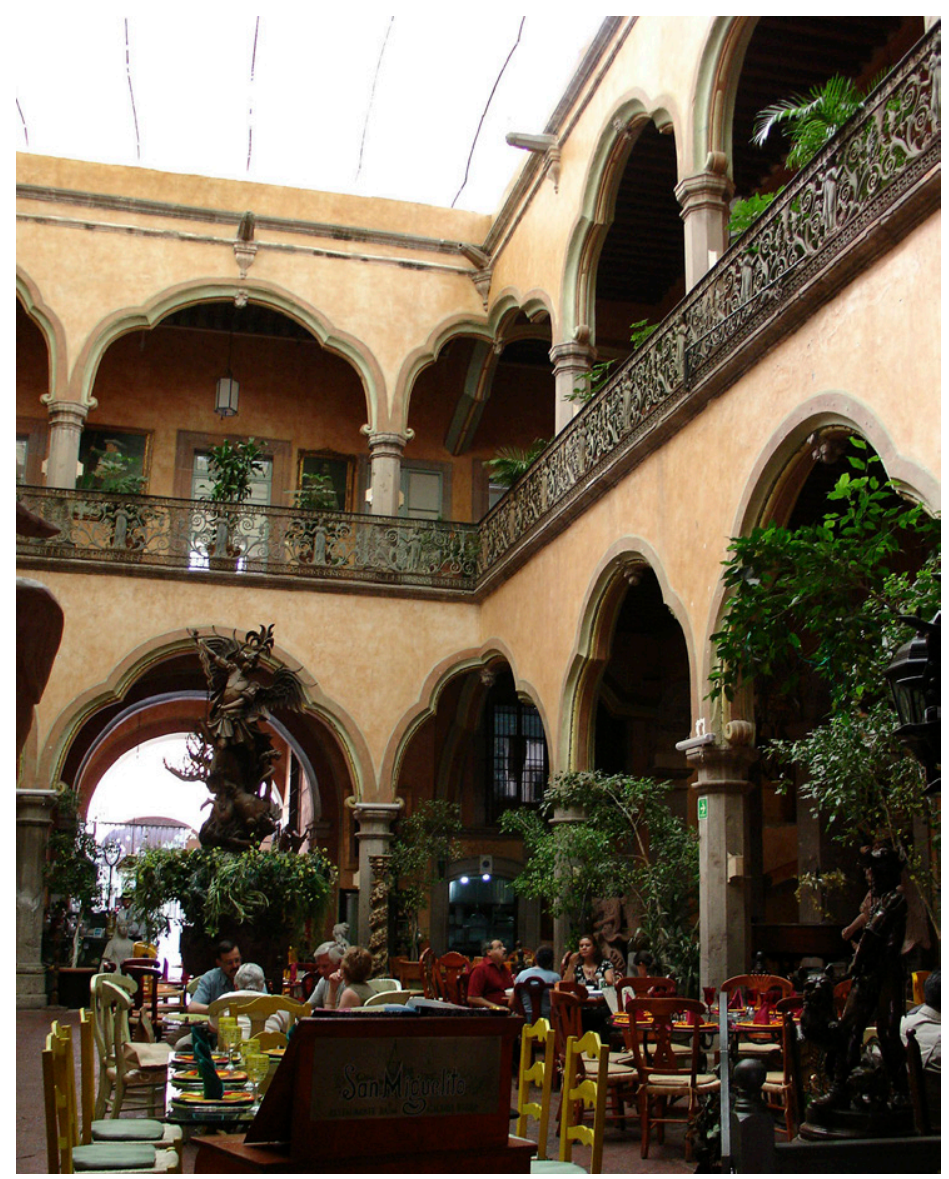

Fig. 13. Patio principal de la Casa de los Cinco Patios. Ciudad de Querétaro. (Fotografía de Martha Fernández).

nes de cortinas talladas en piedra, como las que debieron tener en las habitaciones interiores. (Fig. 12)

En la casa de José de Escandón, conde de Sierra Gorda, ${ }^{40}$ los arcos del primer piso son más sencillos que los del segundo, aunque, en ambos casos, rebajados. En el primer nivel, están constituidos por roleos y conopios diagonales; en el segundo, los roleos se apoyan en las impostas, de donde arrancan lóbulos de diversos tamaños que dan la sensación de ondas en movimiento. En la casa de José Antonio de Urrutia y Arena, marqués del Villar del Águila, ${ }^{41}$ los arcos del segundo nivel también están realizados a base de pequeños lóbulos que rematan en roleos sobre las impostas, pero en este caso su simetría ha provocado que sean calificados como arcos angrelados; no obstante, más que referencia a la heráldica, considero que semejan los volantes de una cortina abierta. ${ }^{42}$

En la Casa de los Cinco Patios, ${ }^{43}$ el principal, tiene solamente arcos trilobulados, que se apoyan con roleos en los capiteles de las columnas octagonales y sus piedras clave están adornadas con hojas. (Fig. 13) En el actual corral de comedias, que fue una casa habitación de un solo nivel, ${ }^{44}$ los arcos son mixtilíneos, imitando ondas o volantes de una tela. Y la variedad de arcos queretanos puede extenderse enormemente, si tomamos en cuenta que no existen dos patios iguales, todos tienen una enorme variedad de soluciones formales.

Es obvio que las cortinas de tela de las casas y palacios novohispanos tuvieron, como ahora, un sentido ornamental y utilitario; eran medios para dotar de privacidad a sus habitantes, al mismo tiempo que decoraban y vestían las habitaciones, por ello, me parece plausible considerar que los arcos de los patios se convirtieran en las cortinas que también los adornaron y vistieron; mostraban ostentación, lujo y riqueza, la misma que debieron poseer sus propietarios; al mismo tiempo, se integraban a los juegos del arte barroco, a sus principios de movimiento y teatralidad.

\footnotetext{
40. El conde pasó a la Nueva España el año de 1727 y se estableció en la ciudad de Querétaro. La casa, por tanto, es del siglo XVIII. Ramírez Montes, 74.

41. El marqués del Villar del Águila se estableció en la ciudad de Querétaro el año de 1721, por tanto, la casa que construyó y habitó es del siglo XVIII. Ramírez Montes, 70.

42. Los arcos del primer piso son de medio punto sin ornamentación.

43. Por sus características arquitectónicas sabemos que es una casa del siglo XVIII.

44. Por sus características arquitectónicas sabemos que es una casa del siglo XVIII.
} 
Aunque no debemos olvidar que el simbolismo formaba parte integral de esa cultura y, por lo mismo, no podemos soslayar el hecho de que, incluso en las casas habitación, permearan principios de esa naturaleza. André Corboz afirma que "las civilizaciones tradicionales sólo pueden vivir en un espacio sagrado y en función de él,” ${ }^{45}$ mientras que, para Mircea Eliade, las ciudades y las casas habitación en las culturas tradicionales eran centros del mundo que reproducían "a escala microcísmica, el universo;" 46 la colocación de la primera piedra significaba precisamente marcar ese centro. En palabras de Eliade, "como la ciudad o el santuario, la casa está santificada, en parte o en su totalidad por un simbolismo o un ritual cosmogónico," para los habitantes es crear "su propio 'mundo' y de asumir la responsabilidad de mantenerlo y renovarlo." ${ }^{47}$ Desde este punto de vista, los arcos-cortinajes de los patios de las casas, tendrían entonces un significado similar al que tienen en los claustros: abrirse a la tienda del cielo, al paraíso que representaba el patio, siempre pleno de árboles y flores, como un jardín, con su fuente al centro. ${ }^{48}$

También es importante mencionar que, en aquel tiempo, las camas solían cubrirse con un dosel de tela que llamaban "cielo," precisamente como una referencia a la idea de la tienda cósmica que Dios había tendido para cubrir la Tierra. Un pabellón, igualmente, cubría el trono que se colocaba en un salón de los palacios de los nobles novohispanos. Este espacio estaba reservado para recibir al rey de España en caso de que visitara ese palacio, cosa que desde luego nunca ocurrió, pero esa sala, más allá de esa posible visita, simbolizaba a la monarquía española. Es decir, que los tronos reales también se encontraban cubiertos por "cielos" de tela. Del mismo modo, la cátedra del arzobispo de México se encontraba bajo palio en un salón del arzobispado, igual que la del papa, en Roma.

\section{Un apunte final}

En su libro Arte y belleza en la estética medieval, Umberto Eco explica que los "autores eclesiásticos que celebran la belleza del arte sagrado insisten luego en su finalidad didascálica... lo que los simples no pueden captar a través de la escritura debe serles enseñado a través de las figuras. ${ }^{\circ 9}$ Esto, por supuesto, no solo es aplicable a las artes visuales, sino que también lo es a la arquitectura, quizá, principalmente a ella. Como expliqué antes, un arco-cortinaje como ingreso a un templo, anuncia la entrada a la tienda cósmica y a la primera revelación del Templo de Salomón, o sea el acceso a la casa de Dios; mientras que, en el patio de un palacio, lo primero que puede transmitir es la riqueza de sus propietarios y el lujo con el que vivían.

Por ello, considero que, si bien es posible describir y definir, desde un punto de vista constructivo los arcos que apreciamos en todas las edificaciones virreinales y nombrarlos con su terminología arquitectónica, también es necesario verlos más allá de ella; ubicarlos en su contexto y tratar de entender las funciones que cumplieron no solamente como elementos estructurales de un edificio, sino también como parte de la sociedad en los espacios por ella construidos. Los arcos, por su propia naturaleza, no son elementos aislados, sino que forman parte del conjunto arquitectónico y son también estructuradores de espacios: ingresos, salidas,

45. André Corboz, "La ciudad como templo," en Dios arquitecto. J. B. Villalpando y el Templo de Salomón (Madrid: Ediciones Siruela, 1995), 53.

46. Mircea Eliade, Lo sagrado y lo profano (Barcelona: Ediciones Paidós Ibérica, 1998), 37.

47. Eliade, 46-47.

48. Desde luego, tenemos que considerar que las fuentes o pozos en las casas solo fueron posible cuando los dueños pudieron conseguir y pagar la merced de agua, pero fue un esfuerzo que con el tiempo lograron implementar incluso en las casas de vecindad.

49. Umberto Eco, Arte y belleza en la estética medieval, trad. Helena Lozano Miralles (Barcelona: Debolsillo, 2015$), 33$. 
pasillos, patios, balcones, etcétera; establecen comunicación con su entorno y también con los seres humanos. De manera que, así como se elaboraron guardamalletas, mantos, cortinas y doseles en piedra, madera o yeso, igualmente los arcos pudieron convertirse en los cortinajes que abrigaron rituales religiosos y sociales.

No olvidemos, sin embargo, que, desde una óptica estrictamente formal, su presencia, durante el desarrollo del arte barroco, también estuvo comprometida con los principios de movimiento, riqueza, dramatismo y teatralidad que acompañaron esa corriente artística en la Nueva España durante los siglos XVII y XVIII, lo que explicaría la variedad de formas que adquirieron durante ese tiempo, son telones que adornaron (y todavía lo hacen) fachadas e interiores de templos, claustros y palacios.

\section{Referencias}

Amerlinck de Corsi, María Concepción. "Pedro de Arrieta y su tiempo." En Pedro de Arrieta. Arquitecto (1692-1738), 35-51. México: Universidad Nacional Autónoma de México, Facultad de Medicina, Consejo Nacional para la Cultura y las Artes, Dirección General de Sitios y Monumentos del Patrimonio Cultural, 2011.

Bargellini, Clara. La arquitectura de la plata. Iglesias monumentales del centro-norte de México. 1640-1750. México: Universidad Nacional Autónoma de México, Instituto de Investigaciones Estéticas, Turner, 1991.

---. "La casa del conde del Valle de Súchil." En Casas señoriales del Banco Nacional de México, 125-152. México: Fomento Cultural Banamex, 1999.

Bérchez, Joaquín. Arquitectura mexicana de los siglos XVII y XVIII. México: Grupo Azabache, 1992.

Corboz, André. "La ciudad como templo." En Dios arquitecto. J. B. Villalpando y el Templo de Salomón, 5177. Madrid: Ediciones Siruela, 1995.

Champeaux, Gérard de, y Dom Sébastien Sterckx. Introducción a los simbolos. Traducido por Abundio Rodríguez, O. S. B. Madrid: Encuentro, 1992.

Eco, Umberto. Arte y belleza en la estética medieval. Traducido por Helena Lozano Miralles. Barcelona: Debolsillo, 2015.

Eliade, Mircea. Lo sagrado y lo profano. Barcelona: Ediciones Paidós Ibérica, 1998.

Fernández, Martha. "Pedro de Arrieta y la arquitectura del barroco mexicano." En El palacio de la Escuela de Medicina, 21-55. México: Universidad Nacional Autónoma de México, Facultad de Medicina, Nacional Financiera, 1994.

---. "El palacio de Iturbide." En Casas señoriales del Banco Nacional de México, 177-206. México: Fomento Cultural Banamex, 1999.

---. Estudios sobre el simbolismo en la arquitectura novohispana. México: Universidad Nacional Autónoma de México, Instituto de Investigaciones Estéticas, Instituto Nacional de Antropología e Historia, 2011.

---. "La imagen de la tienda cósmica en los Santuarios del Tepeyac." Interpretatio. Revista de Hermenéutica 1, no. 2 (septiembre 2016-febrero 2017), 71-87.

---. "Los templos como imagen de la casa de Dios y la puerta del cielo." En Inventario de arte religioso 2017, 150-51. México: Gobierno del Estado de Puebla, Secretaría de Cultura y Turismo, 2018.

Gazetas de México, Castorena y Ursúa (1722), Sahagún y Arévalo (1728-1742). Con introducción de Francisco González de Cosío. México: Secretaría de Educación Pública, 1950. 
González Polo, Ignacio. "Vida y obra del arquitecto Francisco Antonio Guerrero y Torres (1727-1792)." Tesis doctoral, Universidad Nacional Autónoma de México, 2006.

Goycoechea, Juan de. La maravilla immarcescible, y milagro continuado de María Santíssima Señora Nuestra, en su prodigiosa imagen de Guadalupe de México. Compite firmezas con su nuevo Templo, que la copia: adelanta duraciones al Cielo, que a su Efigie traslada; iguala permanencias con el Augusto Sacramento, de quien imita la Milagrosa Presencia en su Pintura. Reproducido en Brading, David A. Nueve Sermones Guadalupanos (1661-1758). México: Centro de Estudios de Historia de México Condumex, 2005.

Guarini, Guarino. Architettura civile. Con introducción de Nino Carboneri y notas y apéndices de Bianca Tavessi La Greca. 1737. Reimpr. Milán: Edizioni il Polifilo, 1968.

Guijo, Gregorio Martín de. Diario, 1648-1664. 2 t. México: Editorial Porrúa, 1952.

Halcón, Fátima. Felipe de Ureña. La difusión del estípite en Nueva España. Sevilla: Universidad de Sevilla, Secretariado de Publicaciones, 2012.

Manrique, Jorge Alberto. "Sagrario Metropolitano de la Catedral de México." En La Catedral de México, coordinado por Xavier Cortés Rocha, Martha Fernández, y Armando Ruiz Castellanos, 313-25. 2.a ed. México: Consejo Nacional para la Cultura y las Artes, 2015.

Marroqui, José María. La ciudad de México. 3 t., 2. a ed. facsimilar. México: Jesús Medina Editor, 1969.

Martínez Rosales, Alfonso. El gran teatro de un pequeño mundo. El Carmen de San Luis Potosí, 1732-1859. México: El Colegio de México, Universidad Autónoma de San Luis Potosí, 1985.

Maza, Francisco de la. San Miguel de Allende. Su historia. Sus monumentos. México: Frente de Afirmación Hispanista, 1972.

Muriel, Josefina. Hospitales de la Nueva España. 2 t., 2. a ed. México: Universidad Nacional Autónoma de México, Instituto de Investigaciones Históricas, Cruz Roja Mexicana, 1991.

Noriega Robles, Eugenio. Zacatecas. Crónica de una ciudad minera. México: San Ángel Ediciones, 1992.

Ramírez Montes, Mina. “Arquitectura civil.” En Querétaro ciudad barroca, coordinado por Juan Antonio Isla Estrada, 49-100. Querétaro: Dirección de Patrimonio Cultural, Secretaría de Cultura y Bienestar Social, Gobierno del Estado de Querétaro, 1988.

---. "Retablos." En Querétaro ciudad barroca, coordinado por Juan Antonio Isla Estrada, 157-92. Querétaro: Dirección de Patrimonio Cultural, Secretaría de Cultura y Bienestar Social, Gobierno del Estado de Querétaro, 1988.

---. Niñas, doncellas, vírgenes eternas. Santa Clara de Querétaro (1607-1864). México: Universidad Nacional Autónoma de México, Instituto de Investigaciones Estéticas, 2005.

Rojas, Pedro. La casa de los Mascarones. México: Universidad Nacional Autónoma de México, Instituto de Investigaciones Estéticas, Imprenta Universitaria, 1985.

Sagrada Biblia, versión directa de las lenguas originales por Eloíno Nácar Fuster y Alberto Colunga, O. P. Madrid: Biblioteca de Autores Cristianos, 1964.

Sescosse Lejeune, Federico. "Catedral de Zacatecas. Nuestra Señora de los Zacatecas." En Catedrales de México, coordinado por Carmen Valles Septién, 185-96. México: CVS Publicaciones, 1993.

Toussaint, Manuel. La Catedral de México y el Sagrario Metropolitano: su historia, su tesoro, su arte. 2.a ed. México: Editorial Porrúa, 1973.

Tovar de Teresa, Guillermo. Bibliografía novohispana de arte. 2 t. México: Fondo de Cultura Económica, 1988.

---. Repertorio de artistas en México. 3 t. México: Grupo Financiero Bancomer, 1995-1997. 


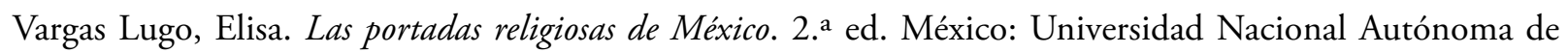
México, Instituto de Investigaciones Estéticas, 1986.

---. La iglesia de Santa Prisca de Taxco. 2. a ed. México: Universidad Nacional Autónoma de México, Instituto de Investigaciones Estéticas, Coordinación de Humanidades, Coordinación de Difusión Cultural, Seminario de Cultura Mexicana, 1999.

Vitruvio Polión, Marco. Los diez libros de arquitectura. Lib. 4, cap. 1. Traducido por Agustín Blánquez. Con prólogo y notas de Agustín Blánquez. Barcelona: Editorial Ibera, 1997. 